\title{
Reflexões sobre o ensino do gênero resumo nas aulas de língua portuguesa na educação de jovens e adultos - EJA
}

\section{Considerations about the teaching of genre abstract in portuguese classes in youth and adult education program}

\author{
Nubia Cristina Prates Santos Oliveira ${ }^{1}$ \\ Maria Eunice Barbosa Vidal ${ }^{2}$
}

\author{
Recebido em: $31 / 03 / 2020$ \\ Aprovado em: 20/04/2020 \\ Publicado em: 30/06/2020
}

\begin{abstract}
Resumo: Este artigo é o resultado de uma pesquisa mais ampla desenvolvida no Programa de Mestrado Profissional em Letras, ProfLetras / UFTM, que buscou identificar as possíveis dificuldades de compreensão textual de uma turma de nono da EJA, em escola pública da cidade de Franca-SP, usando como estratégia interventiva uma sequência de atividades de leitura e escrita com enfoque no gênero resumo. Com o intuito de construir um referencial teórico, baseamo-nos nos estudos de Bakhtin (2003), Geraldi (1997), Marcuschi (2001), entre outros. Em virtude de objetivos didático-metodológicos, também recorremos aos Parâmetros Curriculares Nacionais (PCN) que, desde o final da década de 1990, já propunham o trabalho com os gêneros textuais na educação brasileira. Nesse sentido, verificou-se em que medida o resumo serve como ferramenta para auxiliar os alunos no desenvolvimento de técnicas de estudo de conteúdos escolares, como por exemplo, textos do livro didático da disciplina de Ciências também ofertada a esses estudantes da EJA. Os resultados desta pesquisa, de natureza interdisciplinar, mostraram que as atividades trabalhadas contribuíram para que os alunos se apropriassem de conhecimentos, dedicando maior atenção aos textos lidos na escola. De maneira complementar, os sujeitos da pesquisa relataram que o uso de estratégias apreendidas em sala de aula passou, naturalmente, a fazer parte não somente da sua rotina de estudos, mas também das práticas de leitura do cotidiano. Concluindo: foram relacionados os resultados obtidos, bem como algumas sugestões didático-pedagógicas a professores de língua portuguesa, em consonância com documentos oficiais de ensino, de modo a assegurar a compreensão de conteúdos escolares e estimular o gosto pela leitura.
\end{abstract}

Palavras-chave: EJA; Resumo; Ensino.

\begin{abstract}
This article is the result of a more comprehensive research developed in the Professional Master in Letters Program, ProfLetras / UFTM, which aimed to identify the possible text comprehension difficulties in a ninth year group of youth and adult education program, in a public school in Franca-SP, using as interventional strategy a sequence of reading and writing activities which were focused on the genre abstract. With the goal of building a theoretical referential, we developed our research basis on the studies of Bakhtin (2003), Geraldi (1997), Marcuschi (2001), among others. Because of the methodologic-didactical objectives, we also checked the National Curricular Parameters (PCNs) which, since the end of the 1990 decade, had already proposed the study with the text genres for Brazilian education. So, it was verified in which way the abstract can be a tool to help the students in the development of study techniques of the scholar contents as, for example, texts of the book of the Science class that is also offered to these students of the youth and adult education program. The results of this research, that is an interdisciplinary one, show that the activities done contributed to the gain of knowledge by the students, who had more attention on the texts read in school. Besides, the subjects of the research reported that the use of the strategies learned in class started, naturally, to be part not only of their study routine, but also of their daily reading practices. As a conclusion, the results were related and some of the pedagogic-didactical suggestions of the Portuguese teachers were, in accordance to the official teaching documents as to guarantee the comprehension of scholar contents and stimulate the pleasure for the reading.
\end{abstract}

Keywords: Youth and Adult Education; Abstract; Teaching.

1.Graduação em Letras com habilitação em Literatura. Mestre pelo Programa de Mestrado Profissional em Letras - PROFLETRAS/UFTM. Docente PEB II da Prefeitura Municipal de Franca, atuando na Educação de Jovens e Adultos. ORCID: 0000-0003-1646-8989 E-mail: nubiaprates2@hotmail.com

2.Professora adjunta dos Cursos de Letras da Universidade Federal do Triângulo Mineiro - UFTM e docente permanente do Programa de Mestrado Profissional em Letras - ProfLetras da UFTM. Universidade Federal do Triângulo Mineiro - UFTM. Instituto de Educação, Letras, Artes, Ciências Humanas e Sociais - IELACHS Departamento de Linguística e Língua Portuguesa. ORCID: 0000-0002-8434-143X E-mail: mariaeunice.vidal@uftm.edu.br 
OLIVEIRA, N.C.P.; VIDAL, M.E.B.

\section{INTRODUÇÃO}

\section{Considerações iniciais}

Este texto é um recorte de uma pesquisa de mestrado que teve como principais propósitos identificar as possíveis dificuldades de leitura e escrita de uma turma de $9^{\circ}$ ano da Educação de Jovens e Adultos (EJA), bem como aplicar um plano de intervenção de leitura e escrita por meio do gênero resumo, a fim de verificar o impacto do plano de intervenção junto aos estudantes e, por fim, elaborar uma sequência de atividades para aulas de Língua Portuguesa a partir dos resultados encontrados junto aos alunos após as atividades de intervenção.

Baseamo-nos, principalmente, nos estudos de Bakhtin (2003), Geraldi (1997), Marcuschi (2001), entre outros. Propusemo-nos a trabalhar com a leitura de textos de livros didáticos de componente curricular oferecido na escola, distinto de Língua Portuguesa, de modo a estabelecer um diálogo interdisciplinar e orientar os alunos com estratégias que os auxiliassem a ler com proficiência, buscando, nos textos, as informações relevantes para um bom desempenho avaliativo nos estudos. Para tanto, elegemos o trabalho com o gênero resumo, a fim de identificar se o estudante conseguiu compreender o que leu e o quanto de conhecimento pôde ser produzido a partir do estudo de textos-base.

Ressalte-se que nossa experiência, tanto na docência quanto na pesquisa, tem mostrado que o ensino de leitura e produção textual ainda é um dos maiores desafios ao professor das escolas de ensino público do país. É muito comum observarmos estudantes passando de um ano para outro sem ao menos compreender o que leem, sem autonomia para estudar sozinho e com dificuldades de resumir textos e compreender os diversos conteúdos escolares.

Se o nível de leitura de alunos do ensino regular público ainda hoje é estimado como precário, muito mais deficiente se julgará o de alunos que deixaram a escola na época em que deveriam estar estudando e voltaram após anos distantes dos bancos escolares. É o caso da Educação de Jovens e Adultos (EJA), que enfrenta dificuldades dos mais diversos tipos.

A leitura e a escrita, para esse público, constituem-se como grandes obstáculos para uma satisfatória atuação social. Quando essas pessoas retornam aos estudos - após terem passado anos fora da escola - a sua reinserção no universo do conhecimento é uma tarefa difícil e, por vezes, dolorosa.

Tomando por base esse cenário, verificamos que a desistência escolar se deve, não raras vezes, às dificuldades enfrentadas para conseguir se adaptar ao universo escolar, 
OLIVEIRA, N.C.P.; VIDAL, M.E.B.

necessitando ler para estudar determinados conteúdos ensinados na escola. Decorre daí a nossa hipótese básica de trabalho de que talvez esteja faltando, nas escolas, um ensino mais centrado nas estratégias de leitura com a finalidade de estudo.

Entendemos leitura com finalidade de estudo aquela feita com o objetivo de refletir acerca dos pontos nucleares de determinado texto, uma leitura feita com o fim de compreender mais profundamente as noções principais de um texto.

As dificuldades de leitura ocorrem não somente nas aulas de Língua Portuguesa, mas geram também problemas de compreensão de conteúdos estudados em outras disciplinas escolares. Assim, verificamos que os estudantes têm certos limites no que se refere aos estudos, não conseguindo ler razoavelmente para estudar, ou seja, para compreender as ideias do texto e estabelecer associações com outros temas.

\section{Conceitos operacionais básicos}

Ao pensarmos o trabalho de leitura e escrita no segmento da EJA, logo nos reportamos ao conceito de letramento. Soares (2004) explica o letramento como o uso que se faz da leitura e da escrita nas práticas sociais. A autora ainda afirma que o letramento difere da alfabetização. Então, ser letrado implica, além do fato de saber reconhecer e decodificar o código linguístico, usar a leitura e a escrita como ferramentas para atender às exigências que a sociedade faz do usuário da língua.

Mas o que dizem os documentos oficiais de ensino? De acordo com os Parâmetros Curriculares Nacionais (PCN), "os sujeitos se apropriam dos conteúdos, transformando-os em conhecimento próprio, por meio da ação sobre eles, mediada pela interação com o outro" (BRASIL, 1998, p. 33). Nesse sentido, a proposta desta pesquisa foi a de inserir o aluno da EJA nas práticas de letramento escolar, propiciando-lhe as condições mais efetivas de compreensão dos sentidos em circulação na sociedade de que participa.

Geraldi (1997, p. 80) afirma que o leitor "reconstrói o texto na sua leitura, atribuindoIhe a uma significação". Cada leitor constrói, então, o significado de maneira diferente de outro leitor, uma vez que seus conhecimentos podem ser diversos. Em outras palavras: os sujeitos são particularmente (re) produtores de sua herança cultural. Assim, nenhum texto está acabado, pronto em sua superfície, mas é necessário a construção de sentido feita a partir do sujeito leitor. Para cumprir os objetivos da pesquisa, o nosso entendimento do ato de ler coincide também com essa proposta de Geraldi (1997).

Nesse sentido, aprender a ler deve estar vinculado a ler para aprender. Ler para aprender exige que façamos uma relação daquilo que já sabemos com aquilo que é novo, 
que organizemos e reorganizemos o tempo todo as informações obtidas, que recapitulemos ou façamos uma síntese do que foi compreendido.

Logo, é um processo complexo que exige um grande esforço cognitivo, mas que traz resultados que proporcionam prazer e motivação por poder perceber que houve crescimento e aprendizado por meio da leitura, bem como nos leva a utilizar o conhecimento adquirido para resolução de problemas práticos vivenciados no dia a dia, seja na escola ou fora dela.

Ainda de acordo com o autor, conceber o texto como unidade de ensino / aprendizagem é entendê-lo como um lugar privilegiado para o diálogo com outros textos. Conceber o aluno como produtor de textos é, por sua vez, entendê-lo como participante ativo do diálogo contínuo entre textos e leitores.

Em consonância com essas noções teóricas, no nosso trabalho, a leitura esteve estreitamente vinculada a ler para aprender, isto é, ler de maneira estudiosa para buscar informações e refletir sobre elas. Não se trata, portanto, de decorar os fragmentos do texto, mas de interagir com ele, compreender o que está escrito e relacionar as ideias aos seus conhecimentos adquiridos ao longo da vida.

Assim, nossa intenção de pesquisa foi trabalhar com os alunos estratégias que facilitassem seu processo de inserção no universo escolar e seu bom desempenho nas diferentes atividades escolares. A esse respeito, cita-se:

Estudar é uma ação reflexiva pela qual se quer conhecer e explicar fatos do mundo material, da vida humana, das singularidades pessoais. Neste sentido, é um trabalho intelectual, pressupondo finalidade e compromisso e exigindo condições apropriadas [...] (BRITTO, 2012, p. 56).

O trabalho com os gêneros textuais é de suma importância para garantir ações reflexivas e estudiosas. No final da década de 1990, os gêneros já passaram a se destacar nos documentos oficiais brasileiros sobre educação. A publicação dos Parâmetros Curriculares Nacionais (PCN) foi essencial para inserção do conceito dos gêneros na escola. De acordo com tal documento:

A noção de gênero, refere-se, assim, a famílias de textos que compartilham características comuns, embora heterogêneas, como visão geral da ação à qual o texto se articula, tipo de suporte comunicativo, extensão, grau de literariedade, por exemplo, existindo em número quase ilimitado" (BRASIL, 1998, p. 22).

A partir dos estudos feitos por Bakhtin (2003, p. 261), temos as referências básicas para o ensino a partir dos gêneros. Estes não são imutáveis, mas "relativamente estáveis" 


\section{OLIVEIRA, N.C.P.; VIDAL, M.E.B.}

e variam de acordo com o momento histórico em que estão inseridos, funcionando de acordo com as necessidades comunicativas de cada falante".

O trabalho com o gênero resumo funciona como uma base para ensino/ aprendizagem de leitura, e, nesse sentido, a sala de aula constitui-se como espaço genuíno de interação verbal entre professor e alunos.

Portanto, consideramos as perspectivas do trabalho com os gêneros na escola, uma vez que o resumo é um gênero típico dessa esfera. Em nossa proposta interventiva, o resumo foi utilizado como ferramenta para auxiliar os alunos no desenvolvimento de técnicas de estudo de conteúdos escolares.

O resumo é um gênero cuja importância é essencial no âmbito escolar, uma vez que trabalha com estratégias cognitivas complexas e de suma importância na aprendizagem da leitura e escrita. $\mathrm{E}$, de fato, sem a necessária compreensão do texto, não se configura o resumo. Dessa forma, o resumo se define como

[...] a apresentação concisa dos conteúdos de outro texto (artigo, livro, etc.), que mantém uma organização que reproduz a organização do texto original, com o objetivo de informar o leitor sobre esses conteúdos e cujo enunciador é outro que não o autor do texto original (MACHADO; LOUSADA; ABREUTARDELLI, 2005, p. 91).

O resumo é solicitado em praticamente todas as disciplinas escolares que trabalham com textos; no entanto, baseados em nossa experiência no magistério, notamos que é pouco explorado na escola, por se priorizarem outros gêneros.

$\mathrm{Na}$ verdade, supõe-se que o aluno intuitivamente já consiga resumir um texto, sem precisar de aulas sistematizadas para tal ensino; contudo, nem sempre é o que acontece. Partindo da nossa experiência em sala de aula, notamos que os aprendizes têm muita dificuldade em lidar com este gênero.

Via de regra, o resumo opera praticamente com a redução das ideias de um determinado texto. Antes, porém, de efetuar essa redução, é necessário compreender as informações principais veiculadas pelo texto. Para isso o trabalho com questões sobre a identificação do tema, bem como a relação entre as principais ideias e sua adequada organização são essenciais para o ensino. Somente após a compreensão do texto é que podemos iniciar, de fato, a elaboração do resumo.

Vale destacar que a reescrita também se constituiu como um processo muito importante no trabalho que se realizou em sala de aula. Ao retextualizar o texto-base do livro didático para a formatação de um resumo, o aluno mobilizou estratégias epilinguísticas que contribuíram para a interpretação dos textos e para o seu crescimento acadêmico. 


\section{Procedimentos metodológicos}

Esta seção expõe um recorte de nossa pesquisa qualitativa, que teve como processo metodológico a pesquisa-ação (THIOLLENT, 2009).

As atividades de intervenção foram desenvolvidas numa escola municipal de Educação de Jovens e Adultos na cidade de Franca, interior de São Paulo, nos meses de outubro e novembro de 2018, nas aulas de Língua Portuguesa. Trabalhamos com uma turma de $9^{\circ}$ ano, constituída de um total de 14 alunos, com idade variando entre 19 e 52 anos.

A princípio, a fim de identificar as possíveis necessidades dos estudantes em geral da EJA nessa escola, foi feita uma indagação preliminar. Perguntamos aos alunos qual era a sua maior dificuldade ao voltar a estudar. Foram muitos os relatos; porém, o que mais se destacou foi a imensa dificuldade dos discentes em lidar com as atividades escolares, já que fazia muito tempo que haviam perdido o hábito de estudar, próprio do contexto escolar. Sendo mais específicos, os alunos relataram dificuldades em ler e conseguir compreender os textos escolares, dificuldades em se apropriar de informações importantes para responderem as atividades propostas pelos professores, independentemente do conteúdo programático. Finalmente, dificuldades em estudar para as provas no final de cada etapa

De posse desses dados colhidos não somente na turma dos sujeitos da pesquisa, mas, expandindo um pouco, em boa parte dos discentes de outras classes, optamos por operar, como conduta didática, abrindo caminhos para que os alunos conseguissem compreender o que liam, bem como utilizar as informações apreendidas no texto para que conseguissem participar das avaliações escolares com mais segurança e autonomia.

O trabalho realizado foi de dimensão mais ampla. No entanto, para este artigo em obediência aos limites de espaço, escolhemos as produções de um único aluno, aleatoriamente, para ilustrar como foram feitas e respondidas as atividades e também para apresentar os resultados a que chegamos.

Para preservar a identidade do sujeito da investigação, o discente foi nomeado como Aluno C. Os textos foram transcritos literalmente, preservando a fidelidade da escrita do aluno.

Inicialmente, fizemos uma pergunta (Qual a maior dificuldade que você enfrenta / enfrentou ao voltar a estudar?), a fim de compreender, de modo geral, quais dificuldades envolviam os alunos quando voltaram a estudar. 
Em seguida elaboramos uma intervenção mediadora trazendo estratégias de leitura e compreensão textual. Essa intervenção foi realizada a partir da leitura do texto do livro didático, "Seleção Natural", adotado na escola para o ensino da disciplina de Ciências. Elaboramos questões que envolveram a compreensão do texto, bem como propusemos questões relativas ao conceito de tema, título, ideia principal na construção de resumos.

Foi feita uma observação detalhada das dificuldades que os estudantes encontraram ao ler textos do livro didático de Ciências. Além da observação e análise das atividades, foi aplicado um segundo questionário, com uma questão sobre a experiência dos alunos ao desenvolverem as atividades propostas no plano de intervenção.

Por fim, verificamos quais atividades foram efetivas para o aprendizado dos estudantes, tendo como parâmetro a observação, análise e questionário respondido pelos participantes. Com isso, foi elaborada uma sequência de atividades que poderiam servir de sugestão para as aulas de Língua Portuguesa destinadas a alunos do $9^{\circ}$ ano da EJA.

\section{Atividades para a intervenção \\ Quadro1}

Dividimos as atividades em 5 etapas. O quadro a seguir mostra uma síntese:

Quadro Sinóptico - atividades da intervenção didática

\begin{tabular}{|c|c|}
\hline Etapas & Descrição \\
\hline $\begin{array}{l}\text { Etapa } 1 \text { - Atividade } 1 \\
\text { O MUNDO DO CONHECIMENTO }\end{array}$ & $\begin{array}{l}\text { - Leitura do texto "A seleção natural" } \\
\text { - Questões de compreensão textual e } \\
\text { compreensão do vocabulário }\end{array}$ \\
\hline $\begin{array}{l}\text { Etapa } 2 \text { - Atividades } 2 \text { e } 3 \\
\text { APRENDENDO A ESTUDAR }\end{array}$ & $\begin{array}{l}\text { - Reflexão sobre o que é estudar e sua } \\
\text { importância para a vida escolar } \\
\text { - Trabalho com Tema e Título } \\
\text { - O reconhecimento da ideia principal de } \\
\text { um texto }\end{array}$ \\
\hline $\begin{array}{l}\text { Etapa } 3 \text { - Atividades } 4 \text { e } 5 \\
\text { O RESUMO ESCOLAR }\end{array}$ & $\begin{array}{l}\text { - O resumo escolar } \\
\text { - Resumindo passo a passo }\end{array}$ \\
\hline $\begin{array}{l}\text { Etapa } 4 \text { - Atividade } 6 \\
\text { RESUMINDO }\end{array}$ & $\begin{array}{l}\text { - Iniciando a produção de um resumo do } \\
\text { texto "A Seleção Natural" }\end{array}$ \\
\hline $\begin{array}{l}\text { Etapa } 5 \text { - Atividade } 7 \\
\text { REVISÃO E REESCRITA DO RESUMO }\end{array}$ & $\begin{array}{l}\text { - Devolutiva do resumo revisado pelo } \\
\text { professor } \\
\text { - Reescrita do resumo pelos alunos }\end{array}$ \\
\hline
\end{tabular}

Fonte: Das autoras, 2018.

\section{9 etapa - 0 mundo do conhecimento}

Antes do início das atividades, foi apresentada, detalhadamente, aos alunos a proposta de ensino, os objetivos e a organização do tempo e das aulas. Os alunos se 
OLIVEIRA, N.C.P.; VIDAL, M.E.B.

mostraram dispostos a participar. Nesta aula, partimos do seguinte questionamento: qual a maior dificuldade que você enfrenta / enfrentou ao voltar a estudar? Notamos que as respostas mais recorrentes foram referentes às dificuldades encontradas para estudar satisfatoriamente os conteúdos avaliativos da esfera escolar.

Iniciamos a primeira aula confirmando nosso objetivo: faríamos a leitura de um texto do livro didático de Ciências, a fim de estudar e interpretar o conteúdo e, ao final, produzir um resumo. Foram feitas, a princípio, questões de levantamento de conhecimentos prévios dos alunos, a fim de identificar qual contato eles tinham com os conhecimentos da área de Ciências, tais como: (i) Você costuma ter curiosidade sobre assuntos científicos?; (ii) Onde você costuma buscar resposta para tais curiosidades? Quem escreve esses textos?; (iii) Você costuma estudar no livro didático da escola?; entre outras.

$\mathrm{Na}$ sequência foi entregue a imagem impressa de um sapo camuflado em meio a folhagens, extraída do livro de Ciências:

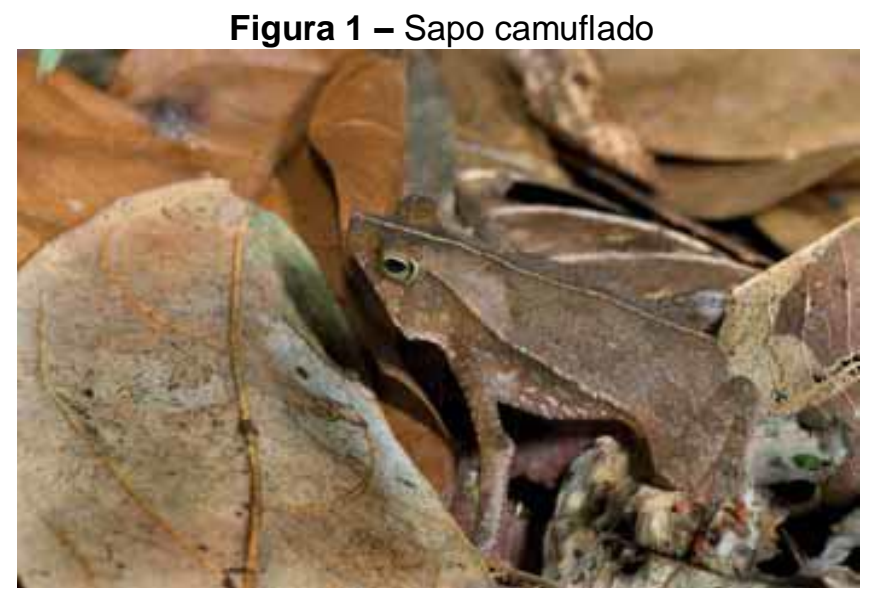

Fonte: São Paulo (2014, p. 35).

Após observarem a imagem acima do anfíbio, foram feitas outras questões baseadas nela, com o intuito de levantar os conhecimentos prévios: (i) O que você enxergou nessa imagem? Viu algum animal? Qual?; (ii) Se houvesse uma borboleta sobre a folhagem, você acha que seria mais fácil enxergá-la?; (iii) E o sapo, você acha que ele se adaptou bem ao ambiente? Por que você acha que ele fez isso?; entre outras.

$\mathrm{Na}$ segunda aula, o texto-base foi entregue aos alunos. Trata-se do texto intitulado "A seleção natural", presente no livro didático (2013, p. 25). Foi solicitada, de início, uma leitura silenciosa do texto e a enumeração dos parágrafos, que totalizaram dezenove.

Depois, fizemos uma leitura compartilhada, respondendo a dúvidas levantadas pelos alunos. Após a leitura compartilhada, foram lidas as questões da primeira parte do livro didático (Compreendendo a Seleção natural), e os alunos foram convidados a responder. 
OLIVEIRA, N.C.P.; VIDAL, M.E.B.

Na terceira aula, os alunos iniciaram as atividades da segunda parte (Vocabulário e Organização textual). As questões foram respondidas dentro do esperado. Durante as aulas, os próprios alunos se ajudaram, sentando-se juntos e providenciando o ajuste das principais ideias conjuntamente.

\section{2a etapa - Aprendendo a estudar}

Na primeira aula dessa etapa, alertamos para a importância de entender que estudar e compreender os conteúdos escolares, entendendo essa tarefa não como um dom, mas como algo perfeitamente possível de se aprender e que requer estratégias cognitivas. Discutimos sobre o que é estudar, o que é necessário fazer para ter bons rendimentos nos estudos, o que fazemos quando queremos saber mais sobre determinado assunto, se grifamos o texto ou fazemos anotações enquanto o professor lê ou explica algum conceito ou definição básica.

Em seguida, partimos para a discussão dos conceitos de tema, título, ideia central e ideias secundárias. Por fim, foi proposta uma atividade contendo um pequeno texto. Os alunos deveriam escrever a respeito da temática e o posicionamento sugerido no texto.

$\mathrm{Na}$ segunda aula, trabalhamos com o conceito de ideia principal. Esse conceito foi complexo de compreender, mas os alunos conseguiram, ao final, atender ao que pedia 0 enunciado da questão. Eles precisariam grifar as ideias principais do $5^{\circ}$ ao $10^{\circ}$ parágrafos do texto.

Explicamos aos alunos a importância dos grifos como estratégia de estudo. Já que através dos grifos conseguimos destacar no texto o que é mais importante e também, posteriormente, podemos articular as informações lidas no texto com outras já conhecidas. Finalmente, os grifos serviram para destacar algumas informações, que posteriormente seriam utilizadas na terceira etapa para produzir o resumo.

\section{3 etapa - O resumo escolar:}

$\mathrm{Na}$ aula anterior, pedimos aos alunos que trouxessem alguns DVD's de filmes que eles tivessem em casa, além de livros que já leram ou que estivessem lendo. Na primeira aula dessa etapa, antes que os alunos chegassem à escola, preparamos alguns materiais para que eles pudessem explorar: livros, que foram disponibilizados pela biblioteca da escola (eles deveriam ler a sinopse contida na contracapa dos livros); imprimimos resumos dos capítulos de uma novela da TV Globo, intitulada Segundo Sol; e capas de DVDs de 
filmes. O objetivo desta aula foi colocar o aluno em contato com a funcionalidade do gênero resumo no meio social.

Pedimos aos alunos que trocassem os materiais entre si e tentassem descobrir o que havia em comum entre os textos que pedimos para eles lerem. Todos observaram muito bem que se tratava de resumos: a sinopse na contracapa do livro, o resumo semanal da novela e a sinopse do filme na contracapa do DVD.

Assim, avaliamos com eles que, na esfera social, o gênero resumo, bem mais do se se poderia imaginar, é bastante utilizado. Cada um desses resumos tinha diferentes enfoques. Saber resumir informações é muito importante e fazemos isso o tempo todo: ao contar acontecimentos do nosso dia, omitimos informações irrelevantes e enfocamos as principais. Para estudar no ambiente escolar, o resumo é um gênero muito importante, uma vez que nos ajuda a compreender as informações mais relevantes no estudo dos conteúdos.

$\mathrm{Na}$ primeira questão das atividades dessa etapa, solicitamos que os alunos encontrassem a temática tratada no texto "Seleção Natural". Em seguida, na próxima questão, inserimos $012^{\circ}$ e $13^{\circ}$ parágrafos para os alunos relerem. Após essa releitura, foi pedido a eles que grifassem a ideia principal destes trechos. Após grifarem, eles deveriam assinalar, entre duas opções, qual melhor resumia o trecho dado. A diferença entre as duas opções era o número de palavras. A primeira opção era um resumo mais conciso. E a segunda opção era uma compilação expandida de ideias. O esperado era que os alunos assinalassem a primeira opção.

$\mathrm{Na}$ terceira questão, inserimos o $14^{\circ}$ e $15^{\circ}$ parágrafos. Os alunos deveriam, novamente, grifar a ideia principal de cada parágrafo. Desta vez, porém, não havia um resumo pronto do trecho para que assinalassem. Eles deveriam tentar resumir, com as próprias palavras, os trechos que grifaram.

Orientamos os alunos a tentarem resumir o trecho para eles mesmos, sem se preocuparem com o parecer do professor, de forma que o resumo seria algo pessoal, feito com suas palavras; uma anotação sobre o texto para que posteriormente pudessem retomar as informações para estudar. Nesta atividade, não importaria tanto a questão de correção gramatical e, sim, se eles conseguiram interpretar as informações do texto para estudar.

$\mathrm{Na}$ última questão desta etapa, eles releram o $17^{\circ}$ e $18^{\circ}$ parágrafos. Também grifaram a ideia principal de cada parágrafo e deviam resumir os trechos grifados. A diferença agora era que nas questões anteriores nós inserimos, antes de eles resumirem, 
OLIVEIRA, N.C.P.; VIDAL, M.E.B.

as expressões "De acordo com o autor" e "Ele afirma que". Nesta questão, eles deveriam lembrar-se de utilizar essas expressões sem que o professor pedisse para apontar 0 posicionamento do autor sugerido pela leitura do texto.

\section{4ㄹ etapa - Resumindo}

Nessa etapa, os alunos foram orientados para, finalmente, elaborarem o resumo do texto-base. Retomamos o conceito de resumo e também relembramos o passo a passo de como elaborar um texto adequado, já trabalhado na etapa anterior.

Cumpre lembrar que cada atividade, de todas as etapas, foi elaborada pensando em uma preparação para a elaboração do resumo final. Então, o esquema do resumo do texto já estava quase pronto, uma vez que as atividades exploraram minuciosamente cada parte do texto dado. Restava aos alunos apenas organizarem as ideias no papel em forma de um resumo único.

Apesar das orientações feitas oralmente em sala de aula, foi necessário ajudar ainda os alunos individualmente, pois as algumas dúvidas ainda prevaleciam. A fim de orientá-los melhor, sugerimos um modelo para que eles pudessem "imitar", a fim de iniciar o resumo. A partir desse modelo, eles continuariam escrevendo seu próprio resumo. Todos os alunos entregaram a tarefa.

\section{5a etapa - Revisão e reescrita do resumo}

Nessa última etapa, os alunos receberam seus resumos de volta já devidamente revisados pela professora. Cada um com um bilhete individual sobre as modificações que eram necessárias em seus respectivos textos. À exceção de um aluno, todo o restante esqueceu de fazer referência ao autor na sua primeira versão. Portanto, antes de reescreverem seus resumos, recordamos a importância de fazer referência ao autor, dando-Ihe os devidos créditos.

Também destacamos a importância que tem essa demarcação da voz do autor do texto-base no gênero textual resumo. O objetivo era que os estudantes também pudessem compreender a responsabilidade em usar informações de outro autor de forma ética, de modo a respeitar a autoria das ideias de terceiros.

Outra dificuldade foi a estruturação dos parágrafos. Assim, fizemos um apanhado das principais dificuldades dos alunos e montamos uma aula para conversar a respeito. Preparamos uma roda de reflexão com todos os alunos, a fim de permitir que eles pudessem reler seus resumos e as orientações que afixamos aos seus textos. 
As principais orientações foram: fazer referência ao autor ou ao livro didático; delimitar adequadamente os parágrafos; ajustar bem a coerência e a coesão, para que as informações ficassem organizadas, claras e coesas; delimitar informações secundárias. Trabalhamos uma a uma, de forma mais detalhada possível.

Para ilustrar melhor, apresentamos em seguida o texto-base e o texto transcrito do Aluno $C$, em sua primeira versão e, na sequência, a sua reescrita.

\section{Texto-base}

\section{A seleção natural}

A seleção natural é um processo em que os seres com características favoráveis em determinado ambiente possuem chance maior de sobrevivência do que os seres sem essas características.

Nesse processo, as características herdadas dos pais, favoráveis à sobrevivência em determinado ambiente, vão se tornando mais comuns na população à medida que novos seres nascem. Ao longo das gerações, as características desfavoráveis passam a ser menos comuns, podendo até desaparecer.

Portanto, a seleção natural é um mecanismo que explica a extinção ou a perpetuação de determinada espécie ao longo do tempo, ou mesmo o surgimento de novas espécies a partir de espécies preexistentes.

Essa é a base da teoria desenvolvida pelo naturalista britânico Charles Darwin (1809-1882) para explicar a evolução e a diversidade da vida na Terra, chamada de teoria da seleção natural.

Em viagem pela América do Sul, quando passou também pelo Brasil, Darwin observou a grande diversidade de animais e plantas. Percebeu que, embora muito semelhantes, os organismos de uma mesma população apresentam pequenas diferenças entre si.

E mais, que essas características diferenciadas, quando favoráveis, fazem que, em determinada população, os indivíduos que as possuem tenham maior probabilidade de sobreviver naquele ambiente, já que elas lhes garantem maior chance de se alimentar ou mesmo de se proteger dos inimigos, por exemplo. Dessa forma, esses indivíduos terão maior chance de se reproduzir e deixar descendentes que formarão a futura população, na próxima geração.

Assim, a ideia básica da teoria da seleção natural é que as características favoráveis tornam-se mais comuns em sucessivas gerações de uma população, enquanto as desfavoráveis tornam-se menos comuns.

Ou seja, a competição pela sobrevivência e as condições ambientais selecionam as características de determinada espécie que favorecem sua sobrevivência e reprodução. Dessa forma, os organismos que possuem características que possibilitam sua sobrevivência diante das condições impostas pelo ambiente têm maior probabilidade de sobreviver do que aqueles que não as possuem.

É por isso que, por exemplo, cactos e camelos sobrevivem em desertos, enquanto samambaias e sapos, geralmente, não. Ao longo de muitas gerações, foram sendo selecionadas as características que permitiam a essas espécies se desenvolver nesses ambientes. Já as que não eram favoráveis foram deixando de existir, com o passar das diferentes gerações.

Cada ser vivo tem características que garantem sua sobrevivência em determinados ambientes, e não em outros. Essas características são transmitidas hereditariamente, de uma geração para outra. Porém, como se observa, os filhos nunca são idênticos aos pais, como também não são idênticos entre si. Sempre há alguma diferença entre eles, chamada variação. Essas características diferentes podem favorecer ou dificultar a sobrevivência dos indivíduos de uma espécie.

Características favoráveis tendem a se manter nos novos descendentes, ajudando a perpetuar essas características na espécie. Quando são desfavoráveis, a tendência é que elas não se mantenham nas novas gerações.

Um bom exemplo entre os animais é a girafa. Acredita-se que, antigamente, havia girafas de pescoço curto e outras de pescoço comprido. Com a competição pelo alimento, as que possuíam pescoço mais longo levavam vantagem sobre as de pescoço mais curto, pois podiam comer tanto as folhas dos galhos mais baixos das árvores quanto as dos galhos mais altos.

Além disso, as girafas de pescoço curto tinham de disputar alimento com outros animais pequenos e mais ágeis, que também se alimentavam dos galhos mais próximos do solo. $O$ resultado desse processo foi a sobrevivência das girafas de pescoço comprido e a extinção das girafas de pescoço curto.

A extinção dos dinossauros pode ser considerada outro exemplo importante de seleção natural. A teoria mais aceita para sua extinção afirma que, no período em que os dinossauros habitavam a Terra, o clima foi estável durante muito tempo, o que propiciou o crescimento de inúmeros tipos de plantas e grande 
variedade de animais. Portanto, haveria alimento e espaço abundantes para animais enormes, como os dinossauros.

No entanto, a rápida mudança climática que teria sido gerada pelo impacto de um imenso meteoro com a Terra teria modificado as condições ambientais. Isso teria ocasionado uma pressão seletiva por conta da escassez de alimentos, o que acabaria provocando a extinção dos dinossauros e de muitos outros seres vivos, que não sobreviveram a essas novas condições.

Em compensação, a extinção em massa ocorrida há 60 milhões de anos criou condições favoráveis para a sobrevivência de várias espécies menores e menos abundantes no período dos dinossauros. As mudanças climáticas também favoreceram o surgimento de novas espécies a partir das que já existiam, pois elas se adaptaram melhor aos novos ambientes, ampliando a biodiversidade na Terra.

[...]

A teoria da evolução fundamenta as explicações científicas sobre o surgimento e a diversificação da vida na Terra.

Pela teoria de Darwin, todos os seres vivos derivam de organismos primitivos que sofreram mudanças aleatórias com o passar do tempo e sobreviveram ou foram extintos pelo processo de seleção natural.

As mudanças no ambiente provocam o aparecimento de novas espécies, que, por sua vez, modificam o ambiente, e assim sucessivamente.

Fonte: São Paulo (2014, p. 39-43).

\section{Resumo do Aluno C - Primeira versão}

A seleção natural é a característica que favorece os seres que melhor nela se adapta e a medida em que novos seres nascem com características herdadas dos pais, vão se adaptando com maior facilidade ao ambiente garantindo a sua sobrevivência.

Isso explica a extinção ou perpetuação ou até mesmo o surgimentos de novas espécies, que teoricamente surgiram de organismos que sofreram mudanças ao longo do tempo através da seleção natural desenvolvida por Charles Darwim, que no Brasil constatou grande diversidade de animais e plantas que embora apresentasse alguma semelhança, haviam diferenças entre sí e tendo observado a grande diversidade pode tambem ver que as características favoráveis são mais comuns em sucessivas gerações e desfavoráveis as menos comuns.

Na primeira versão elaborada pelo aluno $C$, notamos que ele optou por não seguir o início do modelo sugerido pela professora, o que não constitui, a nosso ver, propriamente um problema de escrita. Não se verificou também a referência ao autor. Houve cópia de alguns trechos do texto-base. Faltou também organizar de modo mais claro as informações e demarcar melhor os parágrafos. No entanto, houve a tentativa de reduzir o texto ao formato do gênero resumo. As orientações foram no sentido de refinar um pouco mais as partes constitutivas do resumo.

\section{Resumo do aluno C - Reescrita}

Resumo do texto "Seleção Natural"

De acordo com o texto "seleção natural", a seleção natural é o processo pela qual muitos seres vivos passaram para sobreviver, no qual aqueles que tinham características que se adaptaram mais ao meio ambiente permaneciam vivos, enquanto quem não tinha, era extinto.

O autor explica que a seleção natural é a característica que favorece os seres que melhor nela se adapta.

Revista do SELL, Uberaba/MG (online) - V. 9 n. 1, p. 55-71, jan. /jun. - 2020. 
De acordo com o autor a medida em que novos seres nascem com características herdadas dos pais, vão se adaptando com maior facilidade ao ambiente garantindo a sua sobrevivência.

Para o autor isso explica a extinção ou perpetuação ou até mesmo o surgimento de novas espécies, que teoricamente surgiram de organismos que sofreram mudanças ao longo do tempo, através da seleção natural desenvolvida por Charles Darwin, que no Brasil constatou grande diversidade de animais e plantas que embora apresentasse alguma semelhança, haviam diferenças entre sí e tendo observado a grande diversidade pode também ver que a características favoraveis são mais comuns em sucessivas gerações e desfavoraveis as menos comuns.

Na segunda versão, após a reescrita, já observamos uma organização mais nítida do texto, faltando apenas organizar ainda mais as informações de forma clara e coesa. Haveria necessidade, ainda, de mais uma reescrita do resumo para podermos trabalhar os pontos que poderiam melhorar.

Ao final da intervenção didática, dos 14 (catorze) alunos participantes da pesquisa, 11 (onze) fizeram todas as atividades (alguns com atraso nos prazos das aulas) e 03 (três) deixaram de entregar por completo, cumprindo apenas parte das atividades propostas.

Quanto ao conteúdo dos resumos, alguns aspectos positivos podem ser considerados: todos os resumos contemplaram o texto-base e houve uma adequada transposição das ideias para a feição de resumo. A respeito de alguns textos (cópias do texto-base, distanciadas, portanto, da proposta do resumo), aventamos a hipótese de esse dado estar relacionado à ausência desse tipo de atividade no ensino de outras disciplinas do currículo escolar.

Ao final da atividade de intervenção, contudo, consideramos que houve avanço na escrita e na aprendizagem dos alunos. Evidências na melhora da compreensão leitora dos alunos, no uso adequado dos conectores, no uso das técnicas para resumir ensinadas ao longo das etapas da pesquisa, aparecem nos relatos como a seguir.

Três alunos relataram que passaram a utilizar as estratégias aprendidas durante as aulas em atividades de outros professores. As mais utilizadas foram grifar, no texto, as informações entendidas como relevantes em detrimento das meramente secundárias. Outra estratégia que passou a ser mais utilizada foi montar esquemas sumarizados dos textos lidos.

Assim, os estudantes relataram que tais estratégias não faziam parte de sua rotina de estudos antes da intervenção. A hipótese de que os estudantes tinham dificuldade para adequar-se à rotina de estudos se confirmou, na medida em que eles passaram a utilizar 
OLIVEIRA, N.C.P.; VIDAL, M.E.B.

estratégias de estudo, assimiladas durante a intervenção didática, a fim de ler e compreender estudar textos de outros componentes curriculares.

Para finalizar, em parceria com a professora de Ciências da turma, entregamos aos alunos um texto que seria base para a avaliação final de Ciências do bimestre. Deixamos os alunos à vontade para abordarem o texto como quisessem, uma vez que o objetivo era o estudo individualmente para a prova final da disciplina de Ciências.

Também procuramos verificar se o resumo, como estratégia de estudo, seria escolhido pelos alunos e se funcionaria adequadamente como ferramenta de estudo para todos. O resumo foi escolhido como estratégia de estudo por mais da metade dos alunos.

Finalmente, o que se conseguiu com a pesquisa? Para avaliar se o trabalho de intervenção aplicado foi pertinente para as necessidades dos estudantes, um dia após a avaliação de Ciências, direcionamos aos alunos a seguinte pergunta: "Em que medida as atividades trabalhadas em sala de aula foram úteis para você estudar os textos da matéria para a prova?" A maior parte dos alunos afirmou que as atividades ajudaram muito.

Os resultados dessa pesquisa, portanto, mostraram que as atividades trabalhadas contribuíram para que os alunos prestassem maior atenção aos textos que leram na escola, e utilizassem estratégias como estruturar parágrafos, grifar, fazer esquemas resumitivos que, em razão de essas tarefas serem aparentemente elementares, acabam sendo subestimadas no ensino. Ao contrário, uma vez valorizadas, os alunos relataram, ao final, que as estratégias - até então pouco exploradas em sala de aula - passaram a fazer parte de sua rotina de estudos ganhando destaque, inclusive, na leitura e escrita cotidianas.

\section{CONSIDERAÇÕES FINAIS}

Ao final da pesquisa, consideramos que, inicialmente, a maior dificuldade dos alunos da EJA do $9^{\circ}$ ano do Ensino Fundamental tinha relação com o estudo de textos que circulam no ambiente escolar. Eles não conseguiam ler para estudar os conteúdos escolares. Notamos, no entanto, que a dificuldade era mais densa, uma vez que e pressupunha não somente a leitura, mas também e principalmente a compreensão textual.

Ao propor um trabalho de retextualização dos textos do livro didático de Ciências para o gênero resumo, integramos duas áreas do conhecimento - Português e Ciências a fim de proporcionar um contexto interdisciplinar para afinar o diálogo no ensino, por meio da leitura e escrita de textos que não ficassem circunscritos apenas no âmbito das aulas de Língua Portuguesa.

Revista do SELL, Uberaba/MG (online) - V. 9 n. 1, p. 55-71, jan. /jun. - 2020. 
OLIVEIRA, N.C.P.; VIDAL, M.E.B.

Assim se considerando, a pesquisa demonstrou que investir em práticas de leitura, bem como no ensino de estratégias de leitura na escola, através de atividades interdisciplinares, pode mudar o modo como os alunos leem textos na escola. Os alunos perceberam a importância de usarem estratégias de leitura estudiosa, bem como de elaborarem o resumo do texto lido.

Em outros termos, desenvolveram mecanismos de produção adequada de resumos, a partir da leitura e releitura atenta do texto e, ainda, a identificação de aspectos relevantes no texto-base, a busca pelo tema e suas ideias principais. Importante ainda ressaltar a consideração pelo aluno do seu próprio texto (re)escrito como objeto de estudo.

Podemos apontar algumas conclusões ao final da pesquisa. Primeiro, acreditar que o trabalho com leitura e escrita em sala de aula pode surtir resultados significativos na vida dos alunos da EJA, sobretudo no que concerne ao prosseguimento de sua escolarização. Segundo, com a implementação das atividades de intervenção docente, o nosso olhar enquanto professores mudou muito, passamos a repensar nossa forma de ver os alunos e, principalmente, nossa forma de ensinar, buscando sanar deficiências comumente encontradas no ensino de resumos. Por último, o estímulo gerado pelo Programa de Mestrado Profissional em Letras (ProfLetras) nos desafia a alçar voos mais altos em direção ao ensino e à pesquisa.

\section{REFERÊNCIAS}

BAKHTIN, M. Estética da criação verbal. São Paulo: Martins Fontes, 2003.

BRASIL - MEC / Secretaria de Educação Fundamental. Parâmetros curriculares

nacionais: terceiro e quarto ciclos do ensino fundamental: língua portuguesa. Brasília: MEC/SEF, 1998.

BRITTO, L. P. L. Inquietudes e desacordos: a leitura além do óbvio. Campinas: Mercado de Letras, 2012.

GERALDI, J. W. O texto na sala de aula. São Paulo: Ática, 1997.

MACHADO, A. R.; LOUSADA, E. G.; ABREU-TARDELLI, L. S. O resumo escolar: uma proposta de ensino do gênero. Signum: Estud. Ling. Londrina, n. 8/1, jun. 2005, p. 89101.

MARCUSCHI, L. A. Da fala para a escrita: atividades de retextualização. São Paulo: Cortez, 2001. 
OLIVEIRA, N.C.P.; VIDAL, M.E.B.

SÃO PAULO. Ciências: caderno do estudante. São Paulo: Secretaria de

Desenvolvimento Econômico, Ciência, Tecnologia e Inovação (SDECTI): Secretaria da

Educação (SEE), 2014.

SOARES, Magda. Letramento e alfabetização: as muitas facetas. Revista brasileira de educação, [S.I.], n. 25, p. 5-17, jan/ fev/ mar/abr 2004.

THIOLLENT, M. Metodologia da pesquisa-ação. São Paulo: Cortez, 2009.

\section{Como citar este artigo (ABNT)}

OLIVEIRA, N.C.P.; VIDAL, M.E.B. Reflexões sobre o ensino do gênero resumo nas aulas de língua portuguesa na educação de jovens e adultos - EJA. SELL, Uberaba, MG, v. X, n. X, p. XXX-XXX, 2019. Disponível em: <inserir link de acesso>. Acesso em: inserir dia, mês e ano de acesso. DOI: inserir link do DOI.

\section{Como citar este artigo (APA)}

Oliveira, N.C.P.; Vidal, M.E.B. (2020). Reflexões sobre o ensino do gênero resumo nas aulas de língua portuguesa na educação de jovens e adultos - EJA. SELL, X (X), XXX-XXX. Recuperado em: inserir dia, mês e ano de acesso de inserir link de acesso. DOI: inserir link do DOI. 